\title{
Brain Attack: Dial 911
}

Janet Jankowiak, MD

\section{Stroke Is a Brain Attack}

When a person experiences severe chest pain and a heart attack is suspected, most people know to call 911. However, far fewer people know that a stroke demands equal urgency. A stroke is equivalent to a heart attack of the brain and should be thought of as a brain attack.

Stroke is the third leading cause of death in the United States and a leading cause of serious disability in people of all ages. However, like heart attacks, immediate medical care may increase chances of survival. Therefore, knowing the warning signs of stroke is critical. In addition, knowing the risk factors of stroke may help to prevent a stroke. Information about the risk factors of stroke and warning signs of stroke can be found on the next page.

How many people know the warning signs of stroke or the risk factors of stroke? In this issue of Neurology, Reeves et al. (Reeves MJ, Hogan JG, Rafferty AP. Knowledge of stroke risk factors and warning signs among Michigan adults. Neurology 2002;59:15471552) studied the knowledge of stroke risk factors and warning signs of stroke in a representative statewide sample of Michigan adults. The authors conducted a statewide survey of more than 2,500 adults. People were asked to report the three most important risk factors and the three most important warning signs for stroke.

\section{Stroke Risk Factors and Warning Signs}

A list of correct stroke risk factors and warning signs can be found in tables 1 and 2 .
Table 1 Stroke risk factors

High blood pressure

Smoking

Hyperlipidemia (high level of fats in the blood)

Heart disease

Age

Diabetes

Race

Sex

Physical inactivity

Poor diet

Obesity

Heredity (family history)

Eighty percent of the responders to the survey could list at least one correct risk factor of stroke, but less than $30 \%$ could identify three correct risk factors. High blood pressure and smoking were the two most frequently reported risk factors. Twenty percent of responders could not list any correct risk factors of stroke. Few responders knew that diabetes and cardiovascular (heart) disease are risk factors for stroke. Unfortunately, people at the highest risk for stroke tended to be those with the least awareness of stroke risk factors.

About $70 \%$ of the responders were able to list at least one correct stroke warning sign, but only $14 \%$ could name three. Over $30 \%$ of responders could not list any warn-

Table 2 Stroke warning signs

Sudden numbness or weakness of the face, arm or leg, especially on one side of the body

Sudden confusion

Trouble speaking or understanding

Sudden trouble seeing in one or both eyes Sudden trouble walking

Dizziness, loss of balance or coordination Sudden, severe headache with no known cause ing signs of stroke. Again, these tended to be people at the greatest risk for stroke.

\section{Stroke Must Be Treated in the First 3 Hours}

In this study, people were asked what they would do first if someone were having a stroke. Almost $80 \%$ reported that they would call 911. Almost $90 \%$ knew that stroke victims need immediate medical treatment. However, family members, paid caregivers, and coworkers are much more likely to call 911 than the stroke victim themselves. Patients who call 911 and use ambulance transport arrive at the emergency department significantly earlier than those who do not. Certain medications to treat stroke must be used within the first 3 hours, so early arrival to the emergency department is critical.

This study showed that the general level of awareness regarding stroke risk factors and warning signs of stroke among Michigan adults was not very high. Knowledge of risk factors and warning signs of stroke was poorest in the elderly (75 years and older), men, blacks, persons with less education, smokers, those with high blood pressure, and those with poorer self-rated health. All of these groups are at higher risk of stroke. Other studies have found that people at high risk for stroke who are aware of the risks are more likely to follow measures to prevent stroke.

\section{Stroke Is an Emergency}

Knowing the risk factors for stroke may help to prevent a stroke and knowing the warning signs of stroke may save a life. Stroke is an emergency: call 911. 
WHAT IS STROKE? A stroke, or brain attack, is caused by the sudden loss of blood flow to the brain or bleeding inside the head. A stroke can cause brain cells to die. This damage can cause paralysis, speech problems, loss of feeling, memory and reasoning problems, coma, and possibly death. Fortunately, there are effective ways to prevent stroke. If you develop a stroke, seeking immediate medical attention can help reduce your chances of death and disability.

How Common Is Stroke? Every year, about 750,000 people in the United States suffer a stroke and about 160,000 die. Stroke is the nation's number three killer after heart disease and cancer. Stroke is the number one cause of adult disability.

Stroke Is an Emergency. Call 911 immediately if you or someone you know experiences any of the above warning signs. Jot down the time the symptoms started. Sometimes these warning signs last for only a few minutes and then stop. But, even if that happens or if you feel better, call 911 for help.

\section{RISK FACTORS FOR STROKE THAT CAN BE TREATED OR CHANGED}

- High blood pressure

- Atrial fibrillation (an irregular heart beat)

- Diabetes

- Cigarette smoking

- Hyperlipidemia (high fat level in the blood)

- Alcohol abuse

- Obesity

- Sickle cell disease

\section{WHAT CAUSES A STROKE?}

There are two types of stroke or brain attack. Ischemic stroke is caused by an interruption of blood flow to the brain. Hemorrhagic stroke is caused by bleeding inside the brain.

Eighty percent of all strokes are ischemic. Ischemic stroke can be caused by narrowing of the large arteries to the brain, also known as atherosclerosis. If a clot forms in the neck vessels, pieces can break off and block a brain blood vessel. Clots may also form in the heart and travel by blood flow to the brain vessels where they become lodged.

Hemorrhagic stroke is caused by the bursting of a blood vessel in the brain. It accounts for $20 \%$ of strokes. Subarachnoid hemorrhage occurs when there are weak spots on brain arteries (aneurysms) that burst and cover the brain with blood. Blood vessels in the brain can also burst if they are weakened by high blood pressure, diabetes, and aging. Severe headache usually occurs with this type of stroke, as well as impaired consciousness and vomiting.

\section{WHAT ARE THE TREAT- MENTS FOR STROKE?}

Immediate medical care is critical for the person who is having a stroke or brain attack. New treatments work only if given within a few hours after the onset of a stroke. For example, a clot-busting drug must be given within three hours of stroke onset.

\section{HOW IS STROKE PRE- VENTED?}

Some risk factors-age, sex, race, and a history of stroke in the family-cannot be changed. However, many others can be controlled. Most controllable risk factors relate to the health of the heart and blood vessels. The following can help prevent stroke:

- Having regular medical checkups

- Controlling high blood pressure

- Not smoking-stopping if you do

- Treating heart disease, especially an irregular heart beat called atrial fibrillation

- Improving diet: Avoid excess fat, salt, and alcohol

- Exercising

- Controlling diabetes

- Seeking immediate medical attention for warning signs of stroke

FOR MORE INFORMATION:

American Stroke Association, a Division of the American Heart Association

http://www.strokeassociation.org

National Stroke Association

http://www.stroke.org

AAN: Professional Information http://www.aan.com

AAN: Patient Education

http://www.thebrainmatters.org 


\section{Neurology}

Brain Attack: Dial 911

Janet Jankowiak

Neurology 2002;59;E10

DOI 10.1212/WNL.59.10.E10

This information is current as of November 26, 2002

\section{Updated Information \&}

Services

Permissions \& Licensing

Reprints including high resolution figures, can be found at: http://n.neurology.org/content/59/10/E10.full

Information about reproducing this article in parts (figures,tables) or in its entirety can be found online at:

http://www.neurology.org/about/about_the_journal\#permissions

Information about ordering reprints can be found online:

http://n.neurology.org/subscribers/advertise

Neurology ${ }^{\circledR}$ is the official journal of the American Academy of Neurology. Published continuously since 1951, it is now a weekly with 48 issues per year. Copyright . All rights reserved. Print ISSN: 0028-3878. Online ISSN: 1526-632X.

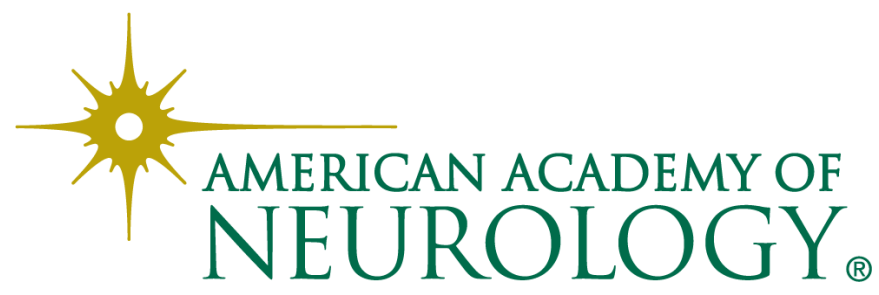

